\title{
Utilizing ultra-wideband with wireless telecommunications applications microstrip
}

\author{
Abhay Chaudhary \\ Department of Computer Science and Engineering, Vellore Institute of Technology, Amaravati, India
}

\begin{tabular}{ll}
\hline \hline \multirow{2}{*}{ Article Info } & ABSTRACT \\
\cline { 3 - 3 } Article history: & $\begin{array}{l}\text { The small aspect, as well as low margins of the microstrip chip amplifier } \\
\text { (MPA) is being used in a contact system. For the last few times within the }\end{array}$ \\
Received Oct 21, 2020 & $\begin{array}{l}\text { last year's research, the majority of work with MPA has been centered } \\
\text { Revised Apr 18, 2021 }\end{array}$ \\
towards designing the portable antenna design. Wireless networking systems \\
may be fitted with a new ultrawideband digital monopoly antenna. \\
Throughout this exponentially changing environment, and dual multi- \\
standard antennas play a crucial role in the implementation of cell towers. \\
This paper presents the nature of an ultra-wideband (UWB)-based antenna \\
array for the shape of a substratum, feeding strategies or openings.
\end{tabular}

Feeding techniques

Microstrip chip amplifier

Operating frequency

Ultra-wideband

This is an open access article under the $\underline{C C B Y-S A}$ license.

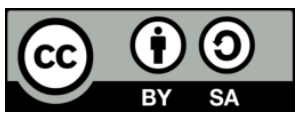

\section{Corresponding Author:}

Abhay Chaudhary

Department of Computer Science and Engineering

Vellore Institute of Technology

AP, Amaravati, India

Email: abhaychaudharydps@gmail.com

\section{INTRODUCTION}

An amplifier that transmits as well as absorbs documentation is also the integrated component of said contact between the microwaves. It is indeed a huge deal, a system built to emanate as well as absorb the electrostatic highly radioactive wave effectively. The amplifier is a transforming sensor that gravitational force strength or pressure on a row in existence composed of an electrical and magnetic system rectangles of movement [1]-[3] on each other.

Usually, to detect the tumorous tissue, the heat imaging organization is completed by a spherical cylinder-shaped collection projection microwave imaging organizations need little projections with omnidirectional radioactivity designs and massive statistics amount. Therefore, that design between a portable amplifier became many among its most critical obstacles of electromagnetic digital imaging across most of the maximum operating range. The reality which placoid monopoly telescopes, including such simple arrangement, mechanical properties and low value, deliver another very enticing approach is notorious [2]-[4]. This is also a notorious truth. Correspondingly, many design monopolies of absolutely different vector illustrations have also been established utilizing automated techniques of design through tests to achieve the perfect cycloid form [5]. Ultra-wideband (UWB) networks also rapidly increased with bandwidth satellite communications. Its Pulse quartet was named by both the federal communication commission UWB systems 3.1-10.6 GHz. Recent UWB technologies were used in the required to authenticate, position and details. Its household control networks of broadband antennas will be commonly used during transmittals, such as high definition televisions (HDTVs), digital video discs (DVDs), also 
monitors personal machines from UWB distribution chains [6], and they have been integrated within those transmitting products.

This horizontal area is by far the most widely encountered area on something like a dielectric substrate. That hexagonal spot antenna is a lengthy portion of the horizontal distribution system through one dimension. Each conductivity amplifier becomes filled because it serves, and since the absolute saturation magnetization including its substratum decreased, a duration including its amplifier reduces. Each way shape or form-stream impedance frequency is around quarter another horizontal ground diameter whereas the air is the substratum for the transmitter. Then right miniature amplifier improves transmittal of propagation.

Slot antenna flux capacitors are separated into two kinds of amplifier duration as well as length. Flux capacitors from a tiny leader called slot antenna diplexer alluded to each other as dielectric substratepatch, but rectifiers have a comprehensive composer. Resonant frequency arises when the scale, including its monopole or surface, is partially- guided. Its propagation of continuous currents now is identical in form as well as leverage, but additional characteristics (e.g. electronic signal effect including divisiveness) differ.

If that amplitude band would be throughout another responder, a patch antenna radiating mostly on width of the surface of something like the substratum becomes approximately parallel. Another significant portion including its symbol is radiated, and therefore that proposed antenna serves like an amplifier. Even as surface measurements will be as large as both the radiologically regulated distance, their guidance, as just an instance, becomes incredibly small, a half-wavelength particle typically shows the 5 to $6 \mathrm{~dB}$ gain with the full beam of 70 to 90 degrees. The transmitter architecture starts through determining that scale of a surface to be used in the transmitter.

This is an improving living standard connected to something like the shield attributable to both the frequency response on either the transmitter emanating sides. That concerned with improving 's fundamental framework throughout Figure 1 device configuration can be seen.
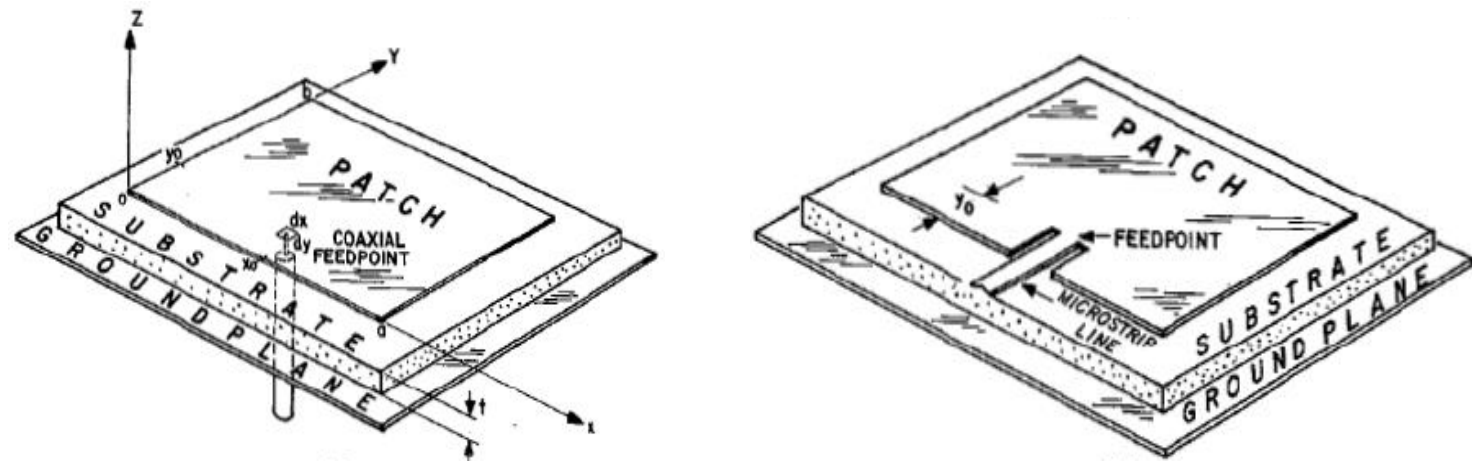

Figure 1. The assembly of microstrip protuberance

\section{LITERATURE REVIEW}

Before the scheduled breakthrough in integrated circuits reduction through mass production throughout 1970, a design including its microstrip line with such a carefully identifying on even an antenna array isolated via an evaluate and understand was unveiled, and some fatal produced an exposure of various settings with a very inexpensive plane utilizing the insulating substratum. With the whole transmitter, different approaches of the mathematical theory were established as well as its implementations applied to very many sectors. Currently, your transmitter model collection mechanism is tiny corner telescopes. The dielectric substrate review of the literature is listed within that portion. The hypothetical antenna meets the voltage standing wave ratio (VSWR) $<2$ specifications, varying from 2.95 to $14.27 \mathrm{GHz}$, with a specific square radiating patch and a smaller scale of $1218 \mathrm{~mm}$ [1], [2], [5], [7]-[9] to improve the knowledge measuring range, two pairs of shaped slits and parasites in the ground plane region being used, thus abounding more astronomical electrical anomalies.

Ruiz-Garcia [3] and VidyaSagar [10] have studied the parametric study of the antenna's thickness. The antennas may be particularly beneficial for smartphone use because they fulfil the specifications of the global system for mobile (GSM) program. Microstrip patch configuration and GSM network antenna are given. The built antenna antennas VSWR are $-3.022 \mathrm{~dB}, 1.0717$.

The concept of the rectangular antenna with a particle swarm optimization (PSO) was suggested by Akyildiz [4]. A standard optimizations algorithm for microstrip patch antenna design is used in this PSO. It 
was provided with the configuration of the rectangular microstrip patch antenna for wideband code division multiple access (WCDMA) using the soft computing process, PSO. A dielectric substratum of 4.4 and height $1,588 \mathrm{~mm}$ has been used to build a microstrip patch antenna. PSO was used to configure parameters including patch duration, width and centre-frequency feed location of $1.95 \mathrm{GHz}$ using Sonnet13.52. PSO saves time compared with patch configuration antennas using an optimization algorithm and even PSO limits centre frequency variance [4], [6]. PSO resonates at exactly $1.95 \mathrm{GHz}$.

Rahali [11] studied a dual-band monopole radio frequency identification/wireless local-area network (RFID/WLAN) lightweight printed monopole antenna (PMA) requirements. The dual-band function is accomplished from the 9-shape folded antenna which is assisted by a non-conductor the electric. Impedance bandwidth is estimated from PMA at $33.13 \%$ with $2.43 \mathrm{GHz}$ and $36.43 \%$ with $2.43 \mathrm{GHz}$. The antenna indicated plays broadband impedance communication, reliable Omni-directions and correct characteristics $(2.5 \mathrm{dBi})$ in the frequency regions of RFID and WLAN. The new PMA was developed for the UWB application by Lin [12].

Virone [13] was to build and evaluate the planar monopoly of broadband antennas utilizing robust multipolar multilevel algorithm. Analyzing the size of the impedance and radiation efficiency of monopolies The electrical integrated field equation (EFIE) moment (MoM) is used. In the meantime, power output is low the quick multipole algorithm (MLFMA) is used in both numerical and operational time. Three flat-band monopolies The floor plans are planned, evaluated and assembled, connected to the final sized planes. The tests are both predicted and calculated. that both monopolies should use the AMPS, GSM900, and DCS channels. A bandpass filter via an I-shaped parasite is suggested that could be incorporated in personal computers. The latest UWB band-rated antenna will conveniently change main frequencies and wavelength to withdraw from the passband [14]-[16].

\section{STUDY OF ANTENNA DESIGNING PARAMETERS}

The architecture of rectangular patch antennas has three basic parameters. The resonant frequency $\left(f_{0}\right)$ first of all an appropriate range must be rendered for the antenna. The frequency spectrum is between 3.1 and $10.6 \mathrm{GHz}$ for ultra-broadband applications. This frequency range will enable the system antenna to work. The thickness of the substrates is the second main parameter for the antenna. Dielectric substratum height $(\mathrm{h})$ of the microstrip. In S-band frequency frequencies, patch antenna with coaxial feed shall be included. The dielectric layer height is also used. The third significant antenna architecture parameter is the dielectric substratum (also dare) in this configuration is $\mathrm{h}=1.6 \mathrm{~mm}$. The transmission line methodology [4] as an illustration can be used in the estimation of antenna parameters. Underneath area depth as (1).

$$
W=\frac{c}{2_{f j} \frac{(\varepsilon r+1)}{2}}
$$

Resonant frequency as (2),

$$
f_{0}=\frac{c}{2 L \sqrt{\varepsilon r}}
$$

and length Le (Effective Length) is chosen as (3).

$$
L_{e}=L+2 \Delta L
$$

\subsection{Ground dimension}

It is necessary to provide a realistic consideration Finite floor plane if the floor plane height is higher by about six times the thickness of the patch thickness of the substratum in the periphery. Hence, the dimensions of the ground plane were given as [17]-[30]. By using these calculations, the central patch size $\mathrm{L} * \mathrm{~W}$ is determined, the ground plane size $\mathrm{Lg} * \mathrm{Wg}$ is determined.

$$
\begin{aligned}
& L_{g}=6 h+L \\
& W_{g}=6 h+W
\end{aligned}
$$

In particular wireless networking programs, it is feasible to use a modern MPA system inside UWB ranges [30-50]. 


\section{CONCLUSION}

The research paper reveals the UWB frequency for wireless networking system implementations was used as a test of the microstrip patch antenna. Since reviewing the literature, it has been established that multi-resonant characteristics like return loss, VSWR, radiation pattern, bandwidth impedance can be enhanced by adjusting the parameters, including the frequency of operation, the size of the ground plane, and the feeding techniques.

\section{REFERENCES}

[1] T. Ahonen, R. Virrankoski and M. Elmusrati, "Greenhouse Monitoring with Wireless Sensor Network," 2008 IEEE/ASME International Conference on Mechtronic and Embedded Systems and Applications, 2008, pp. 403-408, doi: 10.1109/MESA.2008.4735744.

[2] Gerard Rudolph Mendez, " A Wi-Fi Based Smart Wireless Sensor Network for an Agricultural Environment," Master of Engineering Thesis, Assey University, Palmerston North, 2012.

[3] L. Ruiz-Garcia, L. Lunadei, P. Barreiro, and J. I. Robla, "A Review of Wireless Sensor Technologies and Applications in Agriculture and Food Industry: State of the Art and Current Trends," Sensors, vol. 9, no. 6, pp. 4728-4750, 2009, doi: 10.3390/s90604728.

[4] I.F. Akyildiz, W. Su, Y. Sankarasubramaniam, and E. Cayirci, "Wireless sensor networks: a survey," Computer Networks, vol. 38, no. 4, pp. 393-422, 2002, doi: 10.1016/S1389-1286(01)00302-4.

[5] S. Mansour, N. Nasser, L. Karim and A. Ali, "Wireless Sensor Network-based air quality monitoring system," 2014 International Conference on Computing, Networking and Communications (ICNC), 2014, pp. 545-550, doi: 10.1109/ICCNC.2014.6785394.

[6] T. Fukatsu and M. Hirafuji, "Field Monitoring Using Sensor- Nodes with a Web Server," Journal of Robotics and Mechatronics, vol. 17, no. 2, pp.164-172, 2005, doi: 10.20965/jrm.2005.p0164.

[7] C. Gomez, J. Oller and J. Paradells, "Overview and Evaluation of Bluetooth Low Energy: An Emerging LowPower Wireless Technology," Sensors, vol. 12, no. 9, pp. 11734-11753, 2012, doi: 10.3390/s120911734.

[8] L. Ruiz-Garcia and L. Lunadei, "The role of RFID in agriculture: Applications, limitations and challenges," Computers and Electronics in Agriculture, vol. 79, no. 1, pp. 42-50, 2011, doi: 10.1016/j.compag.2011.08.010.

[9] I. A. Aziz, M. H. Hasan, M. J. Ismail, M. Mehat, and N. S. Haron, "Remote Monitoring in Agricultural Greenhouse Using Wireless Sensor and Short Message Service (SMS)," International Journal of Engineering \& Technology IJET, vol. 9, no. 9, pp. 35-43, 2009.

[10] B. VidyaSagar, "Green House Monitoring and Automation using GSM," International Journal of Scientific and Research Publications, vol. 2, no. 5, 2012.

[11] A. Rahali, et al., " Development of a data acquisition and greenhouse control system based on GSM," vol. 3, no. 8, pp. 297-306, 2011, doi: 10.4314/ijest.v3i8.23.

[12] Jzau-Sheng Lin, Yi-Ying Chang, Chun-Zu Liu, Kuo-Wen Pan, "Wireless Sensor Networks and Their Applications to the Healthcare and Precision Agriculture,"in Wireless Sensor Networks, Intechopen, 2011, doi: 10.5772/38738.

[13] G. Virone, A. Wood, L. Selavo, Q. Cao, L. Fang, T. Doan, Z. He, R. Stoleru, S. Lin, and J.A. Stankovic, "An Advanced Wireless Sensor Network for Health Monitoring," [Online]. Available: https://faculty.kfupm.edu.sa/coe/mayez/ps-coe541/sample-projects/Medical-Applications-Wireless-SensorNetworks/10.1.1.64.7346.pdf

[14] Gengyun Wang, "Comparison and Evaluation of Industrial Wireless Sensor Network Standards ISA100.11a and WirelessHART," Master of Science Thesis, Communication Engineering, Department of Signals and Systems, Chalmers University of Technology, Gothenburg, Sweden, 2011.

[15] Delphine Christin, Parag S. More, Matthias Hollick, "Survey on Wireless Sensor Network Technologies for Industrial Automation: The Security and Quality of Service Perspectives," Future Internet, vol. 2, no. 2, pp. 96-125, 2010, doi: 10.3390/fi2020096.

[16] Chwan-Lu Tseng, et al., "Feasibility study on the application of GSM-SMS technology to field data acquisition," Computers and Electronics in Agriculture, vol. 53, no. 1, pp. 45-59, 2006, doi: 10.1016/j.compag.2006.03.005.

[17] A. J. Fehske, F. Richter and G. P. Fettweis, "Energy Efficiency Improvements through Micro Sites in Cellular Mobile Radio Networks," 2009 IEEE Globecom Workshops, 2009, pp. 1-5, doi: 10.1109/GLOCOMW.2009.5360741.

[18] R.-J. Essiambre, G. J. Foschini, G. Kramer, and P. J. Winzer, "Capacity limits of information transport in fibreoptic networks," Phys. Rev. Lett., vol. 101, no. 16, p. 163901, 2008, doi: 10.1103/PhysRevLett.101.163901.

[19] J. Baliga, R. Ayre, K. Hinton, W. V. Sorin and R. S. Tucker, "Energy Consumption in Optical IP Networks," in Journal of Lightwave Technology, vol. 27, no. 13, pp. 2391-2403, July1, 2009, doi: 10.1109/JLT.2008.2010142.

[20] C. Lange, D. Kosiankowski, R. Weidmann and A. Gladisch, "Energy Consumption of Telecommunication Networks and Related Improvement Options," in IEEE Journal of Selected Topics in Quantum Electronics, vol. 17, no. 2, pp. 285-295, March-April 2011, doi: 10.1109/JSTQE.2010.2053522.

[21] K. Hold, "Perception is reality: Internet growth," Broadband World 3, 2001.

[22] N. D. Chan, and S. A. Shaheen, "Ridesharing in North America: Past, Present, and Future," Transport Reviews, vol. 32, no. 1, pp. 93-112, 2012, doi:10.1080/01441647.2011.621557

[23] C. D. Marsan, "Is the Internet shrinking? Nonsense!," IT World Canada, 2002. [Online] Available: https://www.itworldcanada.com/article/uk-police-force-considers-linux-for-desktops/23032. 
[24] A. M. Odlyzko, "Optical Transmission Systems and Equipment for WDM Networking II," in Proc: SPIE (ITCom), B. B. Dingel, W. Weiershausen, A. K. Dutta, and K.-I. Sato, Eds., 2003, vol. 5247, pp. 1-15.

[25] Jul.S. Yin, "Declines in Internet traffic growth won't derail capex," Lightwave Mag., 2004. [Online]. Available: https://www.lightwaveonline.com/business/earnings-statements/article/16647900/declines-in-internet-trafficgrowth-wont-derail-capex

[26] G. K. Cambron, "The multimedia transformation," presented at the Conf. Opt. Fibre Commun. (OFC/NFOEC), Anaheim, CA, plenary, 2006.

[27] M. A. Wegleitner, "Maximizing the impact of optical technology," presented at the Conf. Opt. Fibre Commun. (OFC/NFOEC), Anaheim, CA, plenary, 2007. [Online]. Available: https://www.ofcconference.org/library/images/ofc/PDF/2007/Wegleitner.pdf.

[28] S. D. Elby, "Services from a carrier's perspective," presented at the Conf. Opt. Fibre Commun. (OFC/NFOEC), Anaheim, CA, 2007, paper OThQ1.

[29] J. Stankey, "Infrastructure and regional initiatives," presented at the AT\&T Analyst Conf., 2007. [Online]. Available: https://www.att.com/Common/merger/files/pdf/Stankey_bw.pdf.

[30] P. Magill, "100 Gigabit Ethernet from a Carrier's Perspective," LEOS 2007 - IEEE Lasers and Electro-Optics Society Annual Meeting Conference Proceedings, 2007, pp. 360-361, doi: 10.1109/LEOS.2007.4382427.

[31] C. Labovitz, S. Iekel-Johnson, D. McPherson, J. Oberheide, F. Jahanian, and M. Karir, "ATLAS internet observatory 2009 annual report," presented at the NANOG47, Dearborn, MI, North Amer. Netw. Operators' Group, 2009, [Online]. https://archive.nanog.org/meetings/nanog47/presentations/Monday/Labovitz_ObserveReport_N47_Mon.pdf.

[32] A. Odlyzko, "Traffic growth rates from publicly-observed sites," Minnesota Internet Traffic Studies (MINTS), 2010. [Online]. Available: http://www.dtc.umn.edu/mints/.

[33] A. Ionescu-Graff, The U.S. ex flood Internet video-including some comparisons to Western Europe, Internal document, Alcatel-Lucent, 2008.

[34] H. Kafka, "Business drivers for selecting LTE technology," presented at the LTE: Towards Mobile Broadband, Dallas, TX, ATIS-3GPP, $2009 . \quad$ Anaialable: https://www.adlittle.com/sites/default/files/viewpoints/ADL_UK_Business_Benefits_01.pdf.

[35] J. Borger and H. Uzunalioglu, "Mobile data explosion problem," Internal document, Alcatel-Lucent, 2009.

[36] R. MacKinnon, Peer-to-peer traffic forecast for U.S.A. and selected European countries, Internal document, Alcatel-Lucent, 2009.

[37] S. K. Korotky, "Network global expectation model: a statistical formalism for quickly quantifying network needs and costs," in Journal of Lightwave Technology, vol. 22, no. 3, pp. 703-722, March 2004, doi: 10.1109/JLT.2004.825756.

[38] O. Tamm, C. Hermsmeyer, and A. M. Rush, "Eco-sustainable system and network architectures for future transport networks," Bell Labs Tech. J., vol. 14, no. 4, pp. 311-328, 2010, doi: 10.1002/bltj.20418.

[39] M. Horowitz, E. Alon, D. Patil, S. Naffziger, Rajesh Kumar and K. Bernstein, "Scaling, power, and the future of CMOS," IEEE InternationalElectron Devices Meeting, 2005. IEDM Technical Digest., 2005, pp. 7 pp.-15, doi: 10.1109/IEDM.2005.1609253.

[40] M. Chang et al., "Transistor-and Circuit-Design Optimization for Low-Power CMOS," in IEEE Transactions on Electron Devices, vol. 55, no. 1, pp. 84-95, Jan. 2008, doi: 10.1109/TED.2007.911348.

[41] K. Itoh, "Adaptive circuits for the 0.5-V nanoscale CMOS era," 2009 IEEE International Solid-State Circuits Conference - Digest of Technical Papers, 2009, pp. 14-20, doi: 10.1109/ISSCC.2009.4977291.

[42] M. Bohr, "The new era of scaling in an SoC world," 2009 IEEE International Solid-State Circuits Conference Digest of Technical Papers, 2009, pp. 23-28, doi: 10.1109/ISSCC.2009.4977293.

[43] European Commission, Directorate-General JRC joint research centre, code of conduct on energy consumption of broadband equipment, Version 3, 2008. [Online] Available: https://www.ieee802.org/minutes/nov2008/opening_reports/Code\%20of\%20Conduct\%20Broadband\%20Equipmen t\%20V3\%2021\%20July\%202008\%20draft.pdf.

[44] ITU-T G.984, Gigabit-capable passive optical networks (GPON), 2008. [Online]. Availalble: https://datatracker.ietf.org/documents/LIAISON/file1019.pdf.

[45] 10 Gigabit Capable Passive Optical Networks (XGPON), ITU-T G.987, draft, 2010. [Online]. Available: https://www.itu.int/rec/T-REC-G.987.3/en.

[46] O. Blume, D. Zeller and U. Barth, "Approaches to energy efficient wireless access networks," 2010 4th International Symposium on Communications, Control and Signal Processing (ISCCSP), 2010, pp. 1-5, doi: 10.1109/ISCCSP.2010.5463328.

[47] E. B. Desurvire, "Capacity Demand and Technology Challenges for Lightwave Systems in the Next Two Decades," in Journal of Lightwave Technology, vol. 24, no. 12, pp. 4697-4710, Dec. 2006, doi: 10.1109/JLT.2006.885772.

[48] H. Claussen, L. Ho, and F. Pivit, "Leveraging advances in mobile broadband technology to improve environmental sustainability," Telecommun. J. Australia, vol. 59, no. 1, pp. 4.1-4.18, 2009.

[49] L. A. Barroso and U. Hölzle, "The Case for Energy-Proportional Computing," in Computer, vol. 40, no. 12, pp. 3337, Dec. 2007, doi: 10.1109/MC.2007.443.

[50] J. Baliga, R. Ayre, K. Hinton, and R. S. Tucker, "Architectures for energy-efficient iptv networks," presented at the OFC/NFOEC 2009, San Diego, CA, paper OThQ5, 2009, doi: 10.1364/OFC.2009.OThQ5 